$11-2011$

\title{
Association Between Mental Health Disorders and Juveniles' Detention for a Personal Crime
}

\author{
Patricia A. Stoddard Dare \\ Cleveland State University, p.stoddarddare@csuohio.edu \\ Christopher A. Mallett \\ Cleveland State University, c.a.mallett@csuohio.edu \\ Craig Boitel \\ Cleveland State University, c.boitel@csuohio.edu
}

Follow this and additional works at: https://engagedscholarship.csuohio.edu/clsowo_facpub

Part of the Criminology Commons, Juvenile Law Commons, Mental and Social Health Commons, and the Social Work Commons

How does access to this work benefit you? Let us know!

\section{Publisher's Statement}

This is the accepted version of the article which has been published in final form at http://onlinelibrary.wiley.com/doi/10.1111/j.1475-3588.2011.00599.x/abstract

\section{Recommended Citation}

Stoddard Dare, Patricia A.; Mallett, Christopher A.; and Boitel, Craig, "Association Between Mental Health Disorders and Juveniles' Detention for a Personal Crime" (2011). Social Work Faculty Publications. 14. https://engagedscholarship.csuohio.edu/clsowo_facpub/14

This Article is brought to you for free and open access by the School of Social Work at EngagedScholarship@CSU. It has been accepted for inclusion in Social Work Faculty Publications by an authorized administrator of EngagedScholarship@CSU. For more information, please contact library.es@csuohio.edu. 


\title{
Association between mental health disorders and juveniles' detention for a personal crime
}

\author{
Patricia Stoddard-Dare, Christopher A. Mallett \& Craig Boitel
}

School of Social Work, Cleveland State University, 2121 Euclid Avenue, \#CB320, Cleveland, Ohio 44115-2214, USA.

E-mail: p.stoddarddare@csuohio.edu

Background: Youth involved with juvenile courts often suffer from mental health difficulties and disorders, and these mental health disorders have often been a factor leading to the youth's delinquent behaviours and activities. Method: The present study of a sample population $(N=341)$, randomly drawn from one urban US county's juvenile court delinquent population, investigated which specific mental health disorders predicted detention for committing a personal crime. Results: Youth with attention-deficit hyperactivity disorder and conduct disorder diagnoses were significantly less likely to commit personal crimes and experience subsequent detention, while youth with bipolar diagnoses were significantly more likely. Conclusion: Co-ordinated youth policy efforts leading to early identification and treatment of bipolar disorder symptoms may be necessary.

\section{Key Practitioner Message:}

- Individuals with ADHD and conduct disorder were significantly less likely to commit a personal crime and experience subsequent detention than youth with bipolar diagnosis

- Since youth with bipolar disorder fluctuate between mania and depression, it may be the case that their behaviour is less overly disruptive to others on a consistent basis (i.e. during depressive episodes). Therefore they may attract fewer or less consistent opportunities for professional and lay persons to pursue helpful interventions

- Co-ordinated early identification and treatment of bipolar disorder is required

Keywords: juvenile; offender; bipolar-disorder; mental health; personal crime; detention

\section{Introduction}

Committing personal crimes is an international problem. A study of 11 heterogeneous European and American countries indicates the lifetime prevalence of violent crime to range from $15.8 \%-47.4 \%$ (Junger-Tas, Marshall, \& Ribeaud, 2003), with the highest rates of violent crime occurring in the US. Violent crime, also called personal crime, perpetrated by youth has been increasing in most European countries since the early 1990s (Wittebrood \& Junger, 1999; Junger-Tas, 1996; Junger-Tas et al., 2003). At the same time, mental health disorders remain a top cause of disability worldwide (World Health Organisation, 2005). Therefore, it is not surprising that a majority of youth in the US who have perpetrated violent crimes and are placed in detention have mental health related difficulties (Knoll $\&$ Sickmund, 2010; Teplin et al., 2006). These difficulties pose challenges for not only the youth and family, but also for the juvenile court personnel involved in balancing two primary juvenile justice principles of youth accountability and youth rehabilitation. Finding the right balance is important, and determining how mental health difficulties and disorders affect juvenile court involvement and processing could help judges, probation officers, and other professionals in both prevention and decision-making. This paper reports on findings in the US from one large, urban county in the
Midwest in which the impact of certain mental health disorders have been found to be significantly related to the detention of juvenile offenders following a personal crime. Investigations such as this may be valuable in informing juvenile courts and the child and adolescent field as to how early identification of mental health disorders can provide improved collaborative and preventative efforts. These efforts may also lead to increased diversion for youth who are first-time or lowlevel offenders, and subsequently to fewer youth becoming involved in the juvenile justice system.

\section{Background}

Juvenile delinquency and detention

Internationally, youth delinquency peaks between the ages of 15 and 18 years, although the mean age of onset of violent offences is 13.4 years (Junger-Tas et al., 2003). In the US, 1.7 million youth are annually judged delinquent and 550,000 are placed on probation supervision (National Council on Crime and Delinquency, 2007; Sickmund, 2009). Of these, 350,000 youth are held in almost 600 detention centres (Holman \& Ziedenberg, 2006; Sickmund, Sladky, \& Kang, 2004), and over 100,000 are held in nearly 3000 correctional facilities (Davis et al., 2008; Sickmund, 2006). It is becoming increasingly apparent that these detentions and incarcerations, although necessary for a small 
number of juveniles, generally do more harm than good The confinement experience often leads to continued offending and recidivism (Holman \& Ziedenberg, 2006; Petrosino, Guckenburg, \& Turpin-Petrosino, 2010; Torres \& Ooyen, 2002), while community-based alternatives have been found to decrease re-offending, even for youth who commit serious and sometimes violent crimes (MacArthur Foundation, 2010). In addition, public opinion regarding the US juvenile justice system has been moving from a punitive approach towards a rehabilitative approach, mirroring the juvenile courts' shift over recent years. In fact, recent reviews have identified broad consensus in support of juvenile rehabilitation and a belief that this population of offenders can be reformed (Cullen et al., 2007; Piquero et al., 2010; Piquero \& Steinberg, 2010). Public opinion is quite important in the US, not only as regards the impact on elected legislators but also on juvenile court judges, who in a majority of states are also elected (Annenberg Public Policy Center, 2010).

To safely and prescriptively continue this shift toward juvenile offender rehabilitation, it is important to intervene with at-risk youth and families early on in their contact with the juvenile justice system, and before there is risk of detention or incarceration (Roberts, 2004). One important way is to identify mental health difficulties and disorders, something that many juvenile courts have been doing for quite some time (Mallett \& Julian, 2008; Teplin et al., 2006). Although identification of problem prevalence is an important first step, understanding how these mental health difficulties and which specific mental health disorders - impact upon the youth and their juvenile court involvement is imperative if informed interventions are to be pursued (Grisso, 2008).

\section{Mental health difficulties in juvenile court populations}

In the US, as many as $20 \%$ of the general youth population are identified with a mental health difficulty or disorder (New Freedom Commission on Mental Health, 2003). Within this population, $5 \%-9 \%$ of youth have a serious emotional disturbance that causes substantial impairment in functioning at home or in the community (Office of the Surgeon General, 1999), and another 4\%$8 \%$ of youth have a significant functional impairment (Center for Mental Health Services, 2004; Substance Abuse and Mental Health Services Administration, 2004). These youth have challenges accessing mental health services, have trouble in school settings, and often end up in the juvenile justice system (Bazelon Center for Mental Health, 2009; Simpson et al., 2005; US Department of Education, 2001).

In previous studies of juvenile offender detention facilities, two-thirds of males and three-quarters of females have been found to meet criteria for at least one mental health disorder, with one-tenth also meeting criteria for a substance abuse disorder (Huizinga et al., 2000; Skowyra \& Cocozza, 2007; Teplin et al., 2006; Wasserman et al., 2002). The mental health disorders found include affective disorders (major depressive episode, dysthymia, manic episode), psychotic disorders, anxiety disorders (panic, separation anxiety, overanxious, generalised anxiety, obsessive-compulsive), attention-deficit/hyperactivity disorder (ADHD), disruptive behaviour disorders (conduct, oppositional defiant), and substance use disorders (Grisso, 2008; Mallett, 2006; Teplin et al., 2006). Within the juvenile court population, between $15 \%$ and $20 \%$ have been diagnosed with either depression or dysthymia (Weiss \& Garber, 2003), 13\%-30\% have been diagnosed with ADHD, and 3\%-7\% have been diagnosed with bipolar disorder (Goldstein et al., 2005; Teplin et al., 2002). Also, both conduct disorders and substance use disorders are very prevalent in youth appearing in juvenile courts (upwards of 30\%) (Grisso, 2008), which is not surprising since some of the behaviours associated with these disorders are illegal.

There is growing evidence that mental health difficulties and disorders are linked to later offending behaviour and youth delinquency, although the link may be direct or may lead to additional problems (Heilbrun, Lee, \& Cottle, 2005). Delinquency and childhood depressive disorders are associated, with physical aggression and stealing identified (Loeber \& Keenan, 1994; Takeda, 2000). Aggressive behaviours before age 13 have been found to be predictive of delinquency (Kashani et al., 1999; Tremblay \& LeMarquand, 2001). Hyperactivity and attention problems appear linked to later risk taking and violent offending behaviour (Hawkins et al., 1998; Kashani et al., 1999).

This study continues these inquiries into juvenile offending by identifying which mental health disorders significantly impact upon detention for committing a personal crime among a random sample of youth in one large, US county's juvenile court population. Although personal (and violent) crime offending by juveniles has been decreasing in the US for 15 years, this inquiry is important because annually there are still 140,000 youth arrested nationwide for these types of offences (Puzzanchera, 2009). There were over 4400 personal offence arrests made in the county juvenile court studied. Other researchers have utilised a similar methodology in looking for the links between mental health disorders, aggression, delinquent activities, and juvenile court outcomes (McReynolds, Schwalbe, \& Wasserman, 2010). This study is unique in that it aims to investigate the association between specific mental health disorders and secure detention placement for committing a personal crime. The specific research question was which mental health disorder(s) (ADHD, adjustment, anxiety, bipolar, conduct, depression, oppositional, post-traumatic stress, substance use) predict being sentenced to a secure detention placement for a personal crime?

\section{Method}

\section{Sampling}

Adjudicated delinquent youth in one large, urban Midwestern County served as the base population for this study $(N=2300$ youth who were involved with the courts annually in this county). Three years (2006, 2007 and 2008) were included and therefore the total base population was comprised of 6900 adjudicated delinquent youth, all probation supervised. Calculations indicated that a sample size of $N=360$ would provide a $5 \%$ margin of error and a $95 \% \mathrm{CI}$ (confidence interval), assuming a population proportion of $50 \%$ (Royse et al., 2006).

An electronic number table was used to select a random sample of files from each population year. The final sample consisted of 342 unduplicated youth from the county's juvenile 
court's 2006-2008 population (2006, $N=100 ; 2007, N=137$; $2008, N=105)$. One case was eliminated as an outlier; therefore, 341 cases were analysed.

\section{Data collection}

Existing case records associated with each youth in the study sample were used as the data source. Specifically, the county juvenile court provided files that contained official juvenile court records and mental health assessments for the sample selected. Unidentified data from the case records were coded and entered into a statistical software package. Each case entered was evaluated for proper coding and correct data entry. Inter-coder reliability was high (.96). Since existing case records were used, informed consent procedures were not required. This research was approved by all applicable Institutional Review Boards.

\section{Measurement}

Nine independent and one dependent variable were measured for this study. All variables were measured dichotomously (yes = 1). ADHD, adjustment, anxiety, bipolar, conduct, depression, oppositional, post traumatic stress, and substance use disorders were all assessed using existing mental health case records. All diagnoses were made prior to the youths' first formal involvement with the juvenile court by a licensed mental health professional using the DSM-IV criteria (American Psychiatric Association, 2000). Mental health professionals included psychologists, social workers, psychiatrists, or professional counsellors with experience in official diagnostic assessment. Youth were either self-referred for evaluation or were referred by medical providers, schools, community agencies, or family members who deemed a mental health assessment was necessary. A similar psychiatric nosology system is used worldwide, the ICD-10, and it too includes Bipolar Affective Disorder with a mild or moderate depression diagnosis (World Health Organisation, 1990). Official juvenile court records were used to measure the dependent variable. Youth were coded affirmatively (yes $=1$ ) if they were locked in a secure detention facility as a result of being convicted of a personal crime. Personal crimes, as defined by the state's revised code, included offences committed upon another person (assault, domestic violence, harassment, homicide, sex offenses, kidnapping, menacing, and robbery).

\section{Data analysis}

In order to evaluate the research question and develop a parsimonious model, a two-step analysis was conducted. In the first step, bivariate binary logistic regression was used to determine which variables should be entered into the multivariate model. Each independent variable was regressed separately on the dependent variable. All variables significant at less than .1 in the bivariate mode were then entered into a multivariate model. Bivariate binary logistic regression identified three variables out of the nine to be retained for further analysis - ADHD, bipolar, and conduct disorders. In the second step of data analysis, these three variables were entered into a multivariate binary logistic regression with the dependent variable $($ Method $=$ Enter , Reference $=$ Last $)$.

\section{Results}

In this sample of 341 youth, $13.3 \%(N=45)$ were locked in a secure detention facility as a result of committing a personal crime. ADHD $(N=80,23.5 \%)$, substance use disorder $(N=60,17.6 \%)$, depression $(N=44,12.9 \%)$ and conduct disorder $(N=39,11.4 \%)$ were the most common mental health diagnoses among this sample (see Table 1).

Results of the multivariate binary logistic regression analysis indicated an overall model fit of three predictors -ADHD, bipolar, and conduct disorders. These three variables were statistically reliable in predicting whether a youth was locked in secure detention for committing a personal crime $\left(-2 L L=250 ; X^{2}(3)=\right.$ $16.27, p=.00$ ). The model correctly classified $86.8 \%$ of cases (detailed results are presented in Table 2). Statistics indicated that ADHD and conduct disorder decrease a youth's likelihood of being locked in detention for a personal crime, whereas bipolar disorder was found to increase a youth's likelihood of being so placed.

\section{Discussion}

\section{Mental health disorders}

These results are somewhat surprising, and warrant further investigation. The broad array of offences classified under personal crimes can be caused or motivated through very different means, for a youth who commits a sex offence will undoubtedly differ in motivation from the youth who commits a robbery, or even domestic violence. However, this study found that there was a significant connection between a youth's mental health difficulty (ADHD, conduct disorder and bipolar disorder) and their committing of one of these crimes, with subsequent sentencing to detention. While this connection between mental health problems and juvenile court involvement is well documented, outcomes are not consistent (Huizinga et al., 2000; Loeber et al., 2008; Skowyra \& Cocozza, 2007; Teplin et al., 2006; Wasserman et al., 2002); in this study, finding individual diagnostic differences in the crimes committed is fairly unique.

Three independent variables were significantly related to detention placement for a personal crime. Both ADHD and conduct disorder marginally decrease the likelihood of committing a personal crime and subsequently being placed in detention, while bipolar disorder was found to substantially increase this behaviour and outcome. Indeed, the odds of a youth with bipolar disorder being detained for committing a personal crime is more than eight times higher than those of a youth who does not have this disorder. A full explanation can not be given as to the juvenile court's rationale for secure detention of the youth because other important variables that influence the decision are not included in this analysis. These other influences may include the youth's previous number of offences, history of court supervision, age, number of adjudications, victim impact, specific type of personal crime, and others factors that warrant further investigation.

Regardless of the multifaceted reasons for sentencing a youth to detention, these mental health disorders were related to the committing of a personal crime. Both

Table 1. Frequency of mental health diagnosis in a sample population $(N=341)$ randomly drawn from an urban US county's juvenile court delinquent population

\begin{tabular}{lcc}
\hline Variable (Disorder) & $n$ (yes) & Valid \% (yes) \\
\hline ADHD & 80 & 23.5 \\
Adjustment & 9 & 2.6 \\
Anxiety & 9 & 2.6 \\
Bipolar & 21 & 6.2 \\
Conduct & 39 & 11.4 \\
Depression & 44 & 12.9 \\
Oppositional defiant & 24 & 7.0 \\
Post-traumatic stress & 9 & 2.6 \\
Substance use & 60 & 17.6 \\
\hline
\end{tabular}


Table 2. Multivariate binary logistic regression analysis of those variables significant at less than .1 in bivariate binary logistic regression of results reported in Table 1

\begin{tabular}{|c|c|c|c|c|c|c|}
\hline Variable & B & SE & Wald & $d f$ & $p$ & $\operatorname{Exp}(B)$ \\
\hline ADHD & -1.02 & .36 & 8.00 & 1 & $.01 *$ & .36 \\
\hline Bipolar & 2.18 & 1.08 & 4.09 & 1 & $.04 *$ & 8.87 \\
\hline Conduct & -.91 & .45 & 4.15 & 1 & $.04 *$ & .40 \\
\hline Constant & -2.48 & 1.04 & 5.64 & 1 & .02 & .08 \\
\hline
\end{tabular}

*significant at less than .05

ADHD and conduct disorders include primarily externalising actions and behaviours. This means that the diagnostic criteria used to determine diagnosis and severity are observable behaviour (hyperactive behaviour, fidgety, nervous - ADHD; aggression, violations of norms - conduct disorder). For juvenile court personnel and other professionals working with these youth, these behaviours are often readily apparent. In fact, the behaviours themselves may be directly related to committing the personal crime; for example, the inability to control oneself leading to assault or theft. But these two mental health diagnostic difficulties actually made committing a personal offence less likely. One possible explanation for this contradiction is that since both ADHD and conduct disorder are often readily observable and may impact upon or distract others, it may be that interventions to assist these youth are pursued earlier, and on a more consistent basis. This may explain the slight protective benefit that these two disorders provide.

Conversely, bipolar disorder is considered an internalising and externalising disorder, one where there is the presence or history of one or more major depressive episodes as well as hypomanic episodes. In other words, the youth alternately experiences depressive symptoms (low concentration, feelings of worthlessness, diminished interest), followed by hypomanic symptoms (persistently elevated, expansive, or irritable mood, clearly differentiated from a non-depressed mood) (American Psychiatric Association, 2000). It should be noted that in the United States the diagnosis of bipolar disorder in youth has greatly increased over the past decade, whereas psychosis and other related disorders (primarily externalising) have decreased (National Institute of Mental Health, 2010). One study revealed a forty fold increase in bipolar diagnosis among youth in the last 10 years (National Institute of Mental Health, 2007). It seems that this shift and expansion of bipolar diagnoses may be subsuming psychosis, and other related diagnoses. No diagnosis of psychosis or schizophrenia was found in this sample. This is not surprising given the fact that symptoms of schizophrenia typically begin to emerge between the ages of 15 and 25 years, and many children are misdiagnosed in the early stages of the disorder, or experience a delay in diagnosis that may be attributable in part to the fact that the diagnosis of schizophrenia using DSM-IV criteria requires that symptoms have been persistent for at least 6 months (Nicholson et al., 2001). Although research regarding schizophrenia in the juvenile delinquent population is sparse, one US study suggests that schizophrenia is present in only $1 \%$ of severe delinquents (McManus et al., 1984).

Nonetheless, it was this bipolar diagnosis and combination of depressive and hypomanic symptoms that was significantly related to committing a personal crime. This is interesting because it may be that the youth is unable to handle these symptoms and is acting out because of these challenging 'high highs and low lows'. This is not an uncommon adolescent reaction to these types of symptoms (Schetky \& Benedek, 2002). Since youth with bipolar disorder fluctuate between mania and depression, it may be that their behaviour is less overtly disruptive on a consistent basis (i.e. during depressive episodes). Therefore there may be fewer opportunities for professional and lay persons to pursue helpful interventions.

Furthermore, it is important to note, the impact of bipolar disorder symptoms upon youth may be significantly greater than for adults. Youth's personalities are less fixed, they are susceptible to peer pressure, and they are more impulsive and less responsible in decision-making (Grisso, 2006; Morse, 1997). In addition, there are fundamental differences between juvenile and adult brain development (Damasio \& Anderson, 2003; Fagan, 2008). These developmental differences could make dealing with such symptoms highly problematic and may partially explain their committing of personal crimes. If true, early identification and preventative measures would be paramount to decreasing this offending behaviour.

The value of intervention may be evidenced in the finding thatyouth with ADHD diagnoses were less likely to commit a personal crime. As this diagnosis is most prevalent for primary school aged children (less than 12) (National Institute of Mental Health, 2010), then earlier identification and treatment is possible, and so professional care can be involved before offending behaviours become offending crimes. However, because of this study's methodologicallimitations, it would be premature to recommend community-based interventions prior to improved study design and confirmed findings.

\section{Youth policy systems coordination}

If further research confirms, through the use of community-based youth population samples and multiple controls for other possible covariates, the finding that bipolar disorder is predictive of detention for a personal crime, then significant steps are called for to assist these youth. It is well known that early identification of mental health difficulties in children and youth is a vital step in reducing the later harmful impact of these troubles (New Freedom Commission on Mental Health, 2003; Report of the Surgeon General, 1999). This identification can take place in schools, by family referral, in child welfare settings, and in the juvenile justice system. Professionals working with at-risk children are specifically trained to carry out these identifications, and then to make appropriate treatment plans and recommendations. Police officers, the first contact 
in the juvenile justice system, and juvenile court personnel are becoming more cognizant of the need to identify disorders and disabilities (Grisso, 2008); however, not all juvenile courts are well enough financed or equipped to handle this level of work. In fact, most juvenile courts in the US have quite limited evaluation and testing resources (Rapp-Palicchi \& Roberts, 2004). This poses a significant disconnect between the number of youth who come into juvenile court contact who have significant mental health difficulties and the ability of courts to effectively handle these situations. In particular, bipolar disorder symptoms are often difficult to identify because of the vacillation between depression and hypomania, which requires assessment expertise. This presents a clear opportunity, and arguably need, for the juvenile courts and other professional fields to increase and improve cooperation. Coordinated efforts could include the significant expansion of diversion programs with long-term treatment, as well as the reallocation of juvenile court resources from the later more costly detention stages toward preventative efforts.

\section{Study limitations/future research}

There are limitations to this research that are important to note. First, although this research utilised a random sampling method to select the cases analysed, the sampling frame is only one large Midwestern County in the US. As a result, the generalisability of these results is limited. Second, the dependent variable of interest had a relatively small (although statistically sufficient) number of cases. Third, measurement of the independent variables relied upon existing case records to determine mental health diagnosis. Presumably there were a certain number of youth with undiagnosed mental health issues. Fourth, the -2LL was somewhat inflated, which can be an indication of model fit or simply a reflection of the heterogeneity among delinquent youth. Fifth, the database utilised for this research was created using existing court and mental health records; inaccuracies in these files are unknown. And last, and possibly more important, is the need to expand the research data collection points to community-based youth populations. Using at-risk youth populations in the research, prior to their juvenile court involvement, would allow tracking of these youth outcomes and the ability to fully predict which additional independent variables may influence detention centre placement for committing a personal crime. Similarly, future research should investigate other covariates that may mediate the relationship between mental illness, youth behaviour, and detention placement. As the authors acknowledge, there are a host of other influences on whether courts will detain a juvenile or not. Thus an association purporting to show an influence of mental illness on youth behaviour might be driven principally by other covariates. These should be measured and taken into account in future research.

\section{Conclusion}

A majority of youth who become involved with the juvenile courts in the US, and in particular those sentenced to detention and incarceration facilities, have mental health problems, often severe. Considering that significant numbers of juvenile offenders with these problems are found in the more costly supervision and detention stages of the system, it is important to understand how individual mental health disorders may affect this involvement so that early intervention and prevention measures can be implemented. Future research should aim to collect prospective data from the juveniles themselves.

\section{References}

American Psychiatric Association (2000). Diagnostic and statistical manual of mental disorders - IV, text revisions. Washington, DC: American Psychiatric Association Press.

Annenberg Public Policy Center (2010). Judicial campaigns: Money, mudslinging and an erosion of public trust. Philadelphia, PA: The University of Pennsylvania.

Bazelon Center for Mental Health (2009). Fact sheet on children's mental health, available at http://www.bazelon. org/issues/children/factsheets/index.htm.

Center for Mental Health Services (2004). Mental health, United States. Washington, DC: US Department of Health and Human Services, Public Health Service.

Cullen, F.T., Vose, B.A., Jonson, C.L., \& Unnever, J.D. (2007). Public support for early intervention: Is child saving a 'habit of the heart'? Victims and Offenders, 2, 109-124.

Damasio, A.R., \& Anderson, S.W. (2003). The frontal lobes. In K.M. Heilman \& E. Valenstein (Eds.), Clinicalneuropsychology (4th ed.) (pp. 404-434). New York: Oxford University Press.

Davis, A., Tsukida, C., Marchionna, S., \& Krisberg, B. (2008). The declining number of youth in custody in the juvenile justice system. National Council on Crime and Delinquency, available at http://www.nccd-crc.org/nccd/n_initmhjj_pubs. html.

Fagan, J. (2008). Juvenile crime and criminal justice: Resolving border disputes. The Future of Children, 18, 81-118.

Goldstein, N., Olubadewo, O., Redding, R., \& Lexcen, F. (2005). Mental health disorders. In K. Heilbrun, N.E.S. Goldstein \& R.E. Redding (Eds.), Juvenile delinquency: Prevention, assessment and intervention. Oxford: Oxford University Press.

Grisso, T. (2006). Adolescent's decision-making: A developmental perspective on constitutional provisions in delinquency cases. New England Journal on Criminal and Civil Confinement, 32, 3-15.

Grisso, T. (2008). Adolescent offenders with mental disorders. The Future of Children, 18, 143-162.

Hawkins, J.D., Herrenkohl, T.L., Farrington, D.P., Brewer, D., Catalano, R.F., \& Harachi, T.W. (1998). A review of predictors of youth violence. In R. Loeber \& D.P. Farrington (Eds.), Serious and violent juvenile offenders: Risk factors and successful interventions (pp. 106-146). Thousand Oaks, CA: Sage Publications.

Heilbrun, K., Lee, R., \& Cottle, C. (2005). Risk factors and intervention outcomes: Meta-analyses of juvenile offending. In K. Keilbrun, N. Goldstein \& R. Redding (Eds.), Juvenile delinquency: Prevention, assessment, and treatment. New York: Oxford University Press.

Holman, B., \& Ziedenberg, J. (2006). The dangers of detention: The impact of incarcerating youth in detention and other secure congregate facilities. Baltimore, MD: Annie E. Casey Foundation.

Huizinga, D., Loeber, R., Thornberry, T.P., \& Cothern, L. (2000). Co-occurrence of delinquency and other problem behaviors. Washington, DC: Juvenile Justice Bulletin, Department of Justice.

Junger-Tas, J. (1996). Youth and violence in Europe. Studies on Crime and Crime Prevention, 5 31-58.

Junger-Tas, J., Marhsal, I., \& Ribeud, D. (2003). Delinquency in an international perspective: The international self-reported delinquency study (ISRD). Monroe, New York: Kugler Publications.

Kashani, J., Jones, M., Bumby, K., \& Thomas, L. (1999). Youth violence: Psychosocial risk factors, treatment, prevention, and recommendations. Journal of Emotional and Behavioral Disorders, 7, 200-212. 
Knoll, C., \& Sickmund, M. (2010). Delinquency cases in juvenile court, 2007. Washington, DC: Office of Juvenile Justice and Delinquency Prevention, Office of Justice Programs, US Department of Justice.

Loeber, R., Farrington, D.P., Stouthamer-Loeber, M., \& White, H.R. (2008). Violence and serious theft: Development and prediction from childhood to adulthood. New York: Routledge.

Loeber, R., \& Keenan, K. (1994). Interaction between conduct disorder and its comorbid conditions: Effects of age and gender. Clinical Psychology Review, 14, 497-523.

MacArthur Foundation (2010). Pathways to desistance, available at http://www.modelsforchange.net/reform-progress/ 57 ? src $=$ homeimg.

McManus, M., Alessi, N., Grapentine, W., \& Brickman, A. (1984). Psychiatric disturbance in serious delinquents. Journal of the American Academy of Child Psychiatry, 23, 602-615.

McReynolds, L.S., Schwalbe, C.S., \& Wasserman, G.A. (2010). The contribution of psychiatric disorder to juvenile recidivism. Criminal Justice and Behavior, 37, 204-216.

Mallet, C. (2006). Juvenile court probation-supervised youth: At-risk in Cuyahoga County, Ohio. Corrections Compendium, 31, 1-33.

Mallett, C., \& Julian, L. (2008). Alternatives for Youth's Advocacy Program: Effectively reducing minority youth's detention and incarceration placements in Cleveland, Ohio. Juvenile and Family Court Journal, 59, 1-17.

Morse, S.J. (1997). Immaturity and irresponsibility. Journal of Criminal Law and Criminology, 88, 61-82.

National Council on Crime and Delinquency (2007). And justice for some: Differential treatment of youth of color in the justice system. Available at http://www.nccd-crc.org/ nccd/pubs/2007jan_justice_for_some.pdf.

National Institute of Mental Health (2007). Rates of bipolar diagnosis in youth rapidly climbing, treatment patterns similar to adult. Available at http://www.nimh.nih.gov/ science-news /2007/rates-of-bipolar-diagnosis-in-youth-rapidlyclimbing-treatment-patterns-similar-to-adults.shtml.

National Institute of Mental Health (2010). The numbers count: Mental disorders in America. Available at http:/ / www. nimh. nih.gov/health/publications/the-numbers-count-mentaldisorders-in-america/index.shtml.

New Freedom Commission on Mental Health (2003). Achieving the promise: Transforming mental health care in America, Final Report (p.2). Rockville, MD: DHHS \#SMA-03-3832. Available at http://www.mentalhealthcommission.gov/ reports/reports/htm.

Nicolson, R., Lenane, M., Brookner, F., Gochman, P., Kumra, S., Spechler, L., et al. (2001). Children and adolescents with psychotic disorder not otherwise specified: A 2- to 8-year follow-up study. Comprehensive Psychiatry, 42, 319325.

Office of the Surgeon General (1999). Mental health: A report of the Surgeon General (Chapter 3). Available at http://www. surgeongeneral.gov/library/mentalhealth/toc.html\#chapter3.

Petrosino, A.R., Guckenburg, S., \& Turpin-Petrosino, C. (2010). Formal system processing of juveniles: Effects on delinquency. Campbell Collaboration. Available at http:// www.campbellcollaboration.org/library.php.

Piquero, A.R., Cullen, F.T., Unnever, J.D., Piquero, N.L., \& Gordon, J.A. (2010). Never too late: Public optimism about juvenile rehabilitation. Punishment \& Society, 12, 187-207.

Piquero, A.R., \& Steinberg, L. (2010). Public preferences for rehabilitation versus incarceration of juvenile offenders. Journal of Criminal Justice, 38, 1-6.

Puzzanchera, C. (2009). Juvenile arrests 2008. Washington, DC: US Department of Justice, Office of Justice Programs, Office of Juvenile Justice and Delinquency Prevention.

Rapp-Palicchi, L., \& Roberts, A.R. (2004). Mental illness and juvenile offending. In A.R. Roberts (Ed.), Juvenile justice sourcebook: Past, present, and future (pp. 289-308). New York: Oxford University Press.

Roberts, A.R. (2004). Juvenile justice sourcebook: Past, present, and future. New York: Oxford University Press.
Royse, D., Thyer, B., Padgett, D., \& Logan, T. (2006). Program evaluation: An introduction. Belmont, CA: Thompson Brooks/Cole.

Schetky, D.H., \& Benedek, E.P. (2002). Principles and practice of child and adolescent forensic psychiatry. Washington, DC: American Psychiatric Press.

Sickmund, M. (2006). Juvenile residential facility census, 2002: Selected findings. Washington, DC: Juvenile Offenders and Victims National Report Series. U.S. Department of Justice, Office of Programs, Office of Juvenile Justice and Delinquency Prevention.

Sickmund, M. (2009). Delinquency cases in juvenile court, 2005. US Department of Justice, Office of Justice Programs, Office of Juvenile Justice and Delinquency Prevention. Available at http://www.ncjrs.gov/pdffiles 1/ojjdp/224538.pdf.

Sickmund, M., Sladky, T.J., \& Kang, W. (2004). Census of juveniles in residential placement databook. Available at http://www.ojjdp.ncjrs.org/ojstatbb/cjrp/.

Simpson, G.A., Bloom, B., Cohen, R.A., \& Blumberg, S. (2005). US children with emotional and behavioral difficulties: Data from the 2001, 2002, and 2003 National Health Interview Surveys. Advance Data from Vital and Health Services, 360. Hyattsville, MD: National Center for Health Studies, DHHS \#2005-1250. Available at http://www.cdc.gov/nchs/data/ ad/ad360.pdf

Skowyra, K., \& Cocozza, J.J. (2007). A blueprint for change: Improving the system response to youth with mental health needs involved with the juvenile justice system. Delmar, NY: National Center for Mental Health and Juvenile Justice.

Substance Abuse and Mental Health Services Administration, Office of Applied Statistics (2005). Results from the 2004 national survey on drug use and health. Available at http:// www.oas.samhsa.gov/nsduh/2k4nsduh/2krResults/2k4 Results.htm.

Takeda, Y. (2000). Aggression in relation to childhood depression: A study of Japanese $3^{\text {rd }}-6^{\text {th }}$ graders. Japanese Journal of Developmental Psychology, 11, 1-11.

Teplin, L., Abram, K., McClelland, G., Dulcan, M., \& Mericle, A. (2002). Psychiatric disorders in youth in juvenile detention. Archives of General Psychiatry, 59, 1133-1143.

Teplin, L., Abram, K., McClelland, G., Mericle, A., Dulcan, M., \& Washburn, D. (2006). Psychiatric disorders of youth in detention. Washington, DC: Office of Juvenile Justice and Delinquency Prevention, Juvenile Justice Bulletin, Office of Justice Programs. Available at http://www.ncjrs.gov/pdffiles 1/ojjdp/210331.pdf.

Torres, C., \& Ooyen, M.V. (2002). Briefing paper. New York: Committee on Youth Services. Available at http://webdocs. nyccouncil.info / attachments $/ 56612$. htm?CFID $=1677675 \&$ CFTOKEN $=84562487$.

Tremblay, R.E., \& LeMarquand, D. (2001). Individual risk and protective factors. In R. Loeber \& D.P. Farrington (Eds.), Child delinquents: Development, intervention, and service needs (pp. 137-164). Thousand Oaks, CA: Sage Publications.

US Department of Education, Office of Special Education Programs (2001). Twenty-third annual report to Congress on the implementation of the IDEA: Results.

Wasserman, G.A., McReynolds, L.S., Lucas, C.P., Fisher, P., \& Santos, L. (2002). The voice DISC-IV with incarcerated male youths: Prevalence of disorder. Journal of the American Academy of Child and Adolescent Psychiatry, 41, 314-321.

Weiss, B., \& Garber, J. (2003). Developmental differences in the phenomenology of depression. Development and Psychopathology, 15, 403-430

Whittebrood, K., \& Junger, M. (1999). Trends in geweldscriminaliteit. Tijdschrift voor Criminologie, 41, 250-268.

World Health Organisation (1990). International Classification of Diseases, 10th Revision. Available at http://www.who. int/classifications/icd/en/.

World Health Organisation (2005). Mental health of children and adolescents. WHO European Ministerial Conference on Mental Health, Helsinki, Finland, 12-15 February. 